\title{
Greenland high-elevation mass balance: inference and implication of reference period (1961-90) imbalance
}

\author{
William COLGAN, ${ }^{1}$ Jason E. BOX, ${ }^{1}$ Morten L. ANDERSEN, ${ }^{1}$ Xavier FETTWEIS, ${ }^{2}$ \\ Beáta CSATHÓ, ${ }^{3}$ Robert S. FAUSTO, ${ }^{1}$ Dirk VAN AS, ${ }^{1}$ John WAHR ${ }^{4}$ \\ ${ }^{1}$ Geological Survey of Denmark and Greenland, Copenhagen, Denmark \\ ${ }^{2}$ University of Liège, Liège, Belgium \\ ${ }^{3}$ State University of New York, Buffalo, NY, USA \\ ${ }^{4}$ University of Colorado, Boulder, CO, USA \\ Correspondence: William Colgan<wic@geus.dk>
}

\begin{abstract}
We revisit the input-output mass budget of the high-elevation region of the Greenland ice sheet evaluated by the Program for Arctic Regional Climate Assessment (PARCA). Our revised reference period (1961-90) mass balance of $54 \pm 48 \mathrm{Gt} \mathrm{a}^{-1}$ is substantially greater than the $0 \pm 21 \mathrm{Gt} \mathrm{a}^{-1}$ assessed by PARCA, but consistent with a recent, fully independent, input-output estimate of high-elevation mass balance $\left(41 \pm 61 \mathrm{Gt} \mathrm{a}^{-1}\right)$. Together these estimates infer a reference period high-elevation specific mass balance of $4.8 \pm 5.4 \mathrm{~cm}$ w.e. $\mathrm{a}^{-1}$. The probability density function (PDF) associated with this combined input-output estimate infers an 81 \% likelihood of high-elevation specific mass balance being positive $\left(>0 \mathrm{~cm}\right.$ w.e. $\left.\mathrm{a}^{-1}\right)$ during the reference period, and a $70 \%$ likelihood that specific balance was $>2 \mathrm{~cm}$ w.e. $\mathrm{a}^{-1}$. Given that reference period accumulation is characteristic of centurial and millennial means, and that in situ mass-balance observations exhibit a dependence on surface slope rather than surface mass balance, we suggest that millennial-scale ice dynamics are the primary driver of subtle reference period high-elevation mass gain. Failure to acknowledge subtle reference period dynamic mass gain can result in underestimating recent dynamic mass loss by $\sim 17 \%$, and recent total Greenland mass loss by $\sim 7 \%$.
\end{abstract}

KEYWORDS: ice-sheet mass balance

\section{INTRODUCTION}

The transfer of terrestrial ice into the sea accounted for over half the $3.3 \pm 0.4 \mathrm{~mm} \mathrm{a}^{-1}$ sea-level rise observed during 1993-2007 (Cazenave and Llovel, 2010). While the Greenland ice sheet is believed to have been in near balance under the pre-1990 climate, recent climate warming has resulted in an increasingly negative ice-sheet mass balance (Rignot and others, 2008). The Greenland ice sheet is now the single largest cryospheric source of sea-level rise. During 2000-11, the mass balance of Greenland land ice was $-211 \pm 37 \mathrm{Gta}^{-1}$, equivalent to a contribution to sea-level rise of $0.58 \pm 0.10 \mathrm{~mm} \mathrm{a}^{-1}$ (Shepherd and others, 2012). Greenland ice loss is a consequence of both surface massbalance processes, which increase meltwater runoff, and ice-dynamic processes, which increase iceberg discharge. While the surface mass balance and ice-dynamic components of recent Greenland ice loss were approximately equal over 2000-08 (Van den Broeke and others, 2009), the surface mass-balance component of Greenland ice loss appears to have outpaced the ice-dynamic component since about 2005 (Enderlin and others, 2014).

The transient glacier continuity equation describes mass balance $(\dot{m})$ as the sum of climatic surface mass balance $(\dot{b})$ and horizontal divergence of ice flow (or ice dynamics; $\nabla Q)$ :

$$
\dot{m}=\dot{b}-\nabla Q
$$

To assess the recent ice loss stemming from changes in either surface mass balance $(\Delta \dot{b})$ or ice dynamics $(\Delta(\nabla Q))$, contemporary observational period ('obs') values of $\dot{b}$ and $\nabla Q$ are differenced from analogous reference period ('ref') values representative of near-equilibrium conditions:

$$
\begin{gathered}
\Delta \dot{b}=\dot{b}_{\text {obs }}-\dot{b}_{\text {ref }} \\
\Delta(\nabla Q)=\nabla Q_{\text {obs }}-\nabla Q_{\text {ref }}
\end{gathered}
$$

The assumption of equilibrium mass balance during the 1961-90 reference period underpins canonical partitions of recent Greenland ice loss into surface mass-balance and ice-dynamic components (Van den Broeke and others, 2009; Enderlin and others, 2014). Within this framework, which explicitly assumes that $\dot{m} \approx 0$ during the reference period, relatively small reference period imbalances can have relatively large implications on partitioning contemporary mass loss. For example, underestimating reference period mass balance subsequently underestimates ice loss since the reference period by an equivalent magnitude. An impetus therefore exists to constrain subtle reference period mass-balance signals for the purposes of accurately quantifying and partitioning contemporary ice-sheet mass loss.

We revisit the input-output mass-balance assessment of the high-elevation region of the Greenland ice sheet initially performed by the Program for Arctic Regional Climate Assessment (PARCA; Thomas and others, 2000, 2001). We combine this reassessed high-elevation mass balance with an analogous, fully independent input-output estimate (Andersen and others, 2015) and assess a combined specific mass balance that infers subtle high-elevation mass gain during the reference period. While the ice-sheet area within the PARCA perimeter we consider accounts for only $\sim 58 \%$ of the ice-sheet extent, this challenges the notion of 

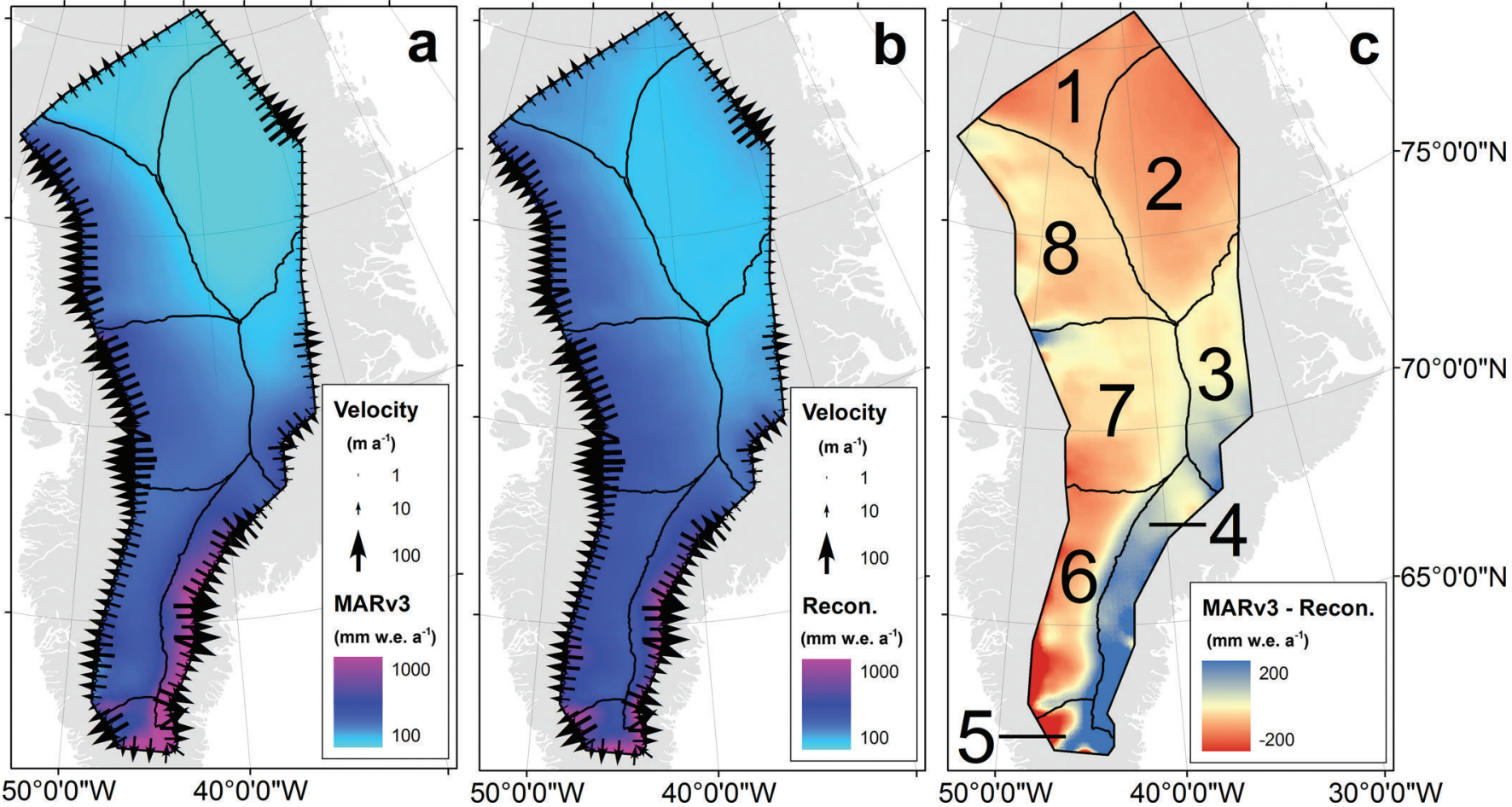

Fig. 1. High-elevation surface mass balance during the 1961-90 reference climatology period simulated by MARv3 (a; Fettweis and others, 2013) and reconstructed from ice cores (b; Box and others, 2013), and the difference field (c). Observed 1995 ice surface velocities of 161 flux gates shown around the PARCA perimeter. Numbers denote basins. Colour bars saturate at minimum and maximum values.

equilibrium mass balance during the 1961-90 reference period. We posit that non-trivial long-term dynamic mass gain, associated with ongoing glacial-interglacial changes in ice-sheet geometry, should be considered in massbalance partition as an independent term, distinct and opposite in sign from recent short-term dynamic mass loss.

\section{METHODOLOGY}

We adopt the high-elevation study area defined by PARCA, which approximately follows the $2000 \mathrm{~m}$ elevation of the Greenland ice sheet (Thomas and others, 2000, 2001). Following the input-output approach of Thomas and others (2001) for determining high-elevation mass balance, we difference ice outflow from the PARCA perimeter from surface mass balance (or net accumulation) integrated across the enclosed PARCA area. We subdivide the PARCA area into the eight major drainage basins delineated by Zwally and others (2012). Within each basin, we assess mass input, mass output and mass balance, and their associated uncertainties (Table 1). Mass input is characterized as mean annual surface mass balance during the 196190 reference climatology period. This is the period during which the ice sheet is conventionally believed to have been in near-equilibrium mass balance (Van den Broeke and others, 2009). Mass output is characterized using 1995 ice velocities derived from repeated stake measurements made using precise GPS observations (Thomas and others, 2001). Under the assumption that ice velocity along the PARCA perimeter has not changed significantly since 1961 (Joughin and others, 2010), we take the mass-balance estimate we generate as representative of the 1961-90 reference period.

We estimate surface mass balance within the PARCA perimeter in two ways: via the regional climate model MAR (Modèle Atmosphérique Régional) (version 3; Fettweis and others, 2013) and via an ice-core-derived reconstruction (Box and others, 2013; Fig. 1). Following identification of an accumulation bias in MAR (version 2), which resulted in a root-mean-square error (RMSE) of $46 \%$ with in situ surface mass-balance observations above $1500 \mathrm{~m}$ elevation (Vernon and others, 2013), MARv3 has been tuned with 86 spatially distributed ice-core-derived accumulation records (Box and others, 2013). MARv3 now reproduces point surface massbalance observations with an RMSE of $\sim 20 \%$ and ice-sheetwide net surface mass balance with an uncertainty of $\sim 10 \%$

Table 1. Mass balance in the eight major drainage basins within the PARCA perimeter during the 1961-90 reference period. We reassess mass output from each basin by combining PARCA and more recent observations. Mass input to each basin is estimated as the mean of an ice-core reconstruction (Box and others, 2013) and regional climate modelling (Fettweis and others, 2013). Values have been rounded to the nearest $\mathrm{Gt} \mathrm{a}^{-1}$

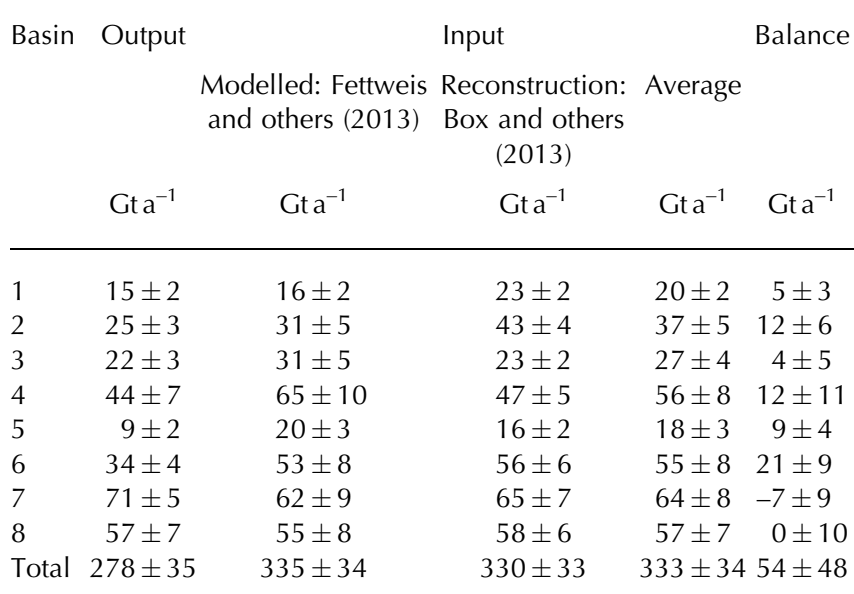



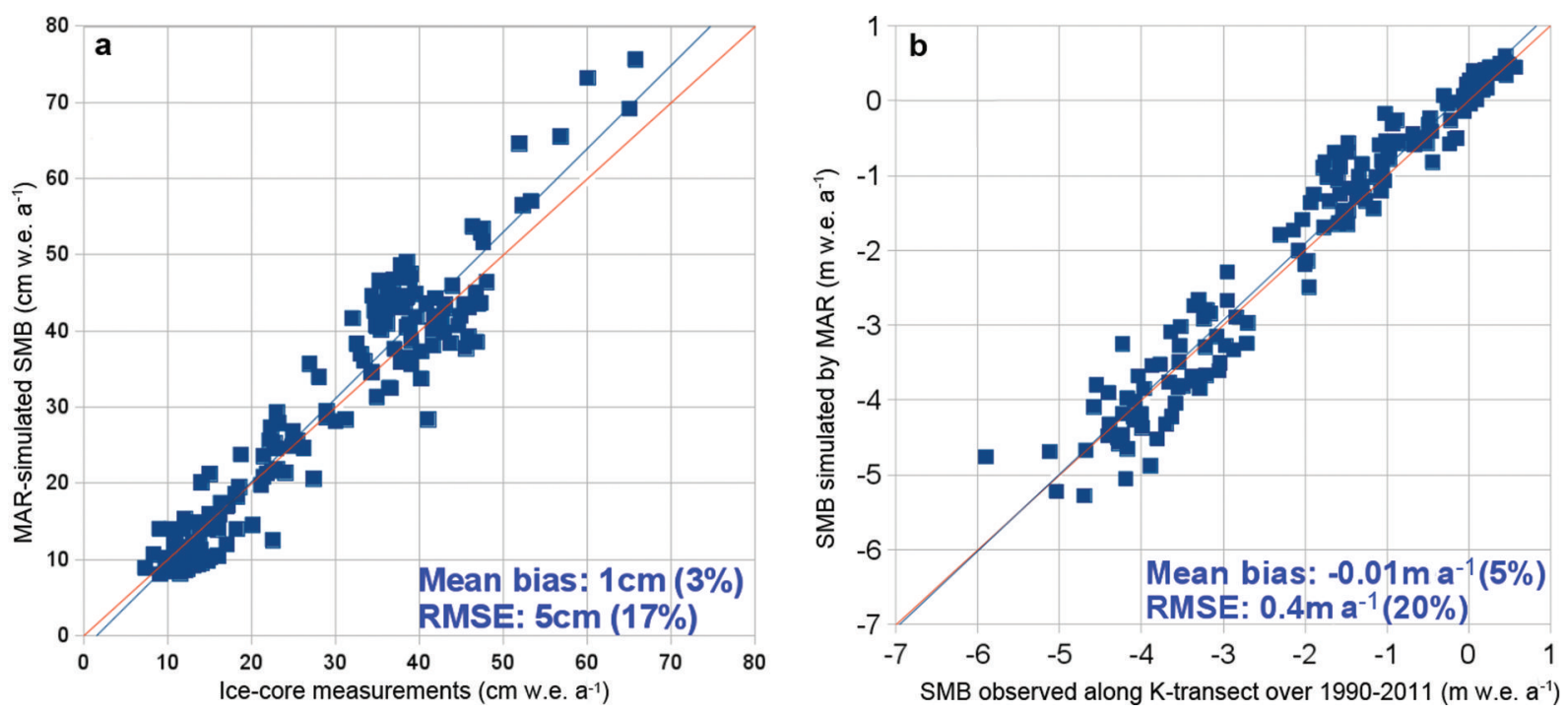

Fig. 2. Evaluation of MARv3 modelled surface mass balance (SMB) versus long-term mean SMB observed at ice-core sites in the accumulation zone (a; Cogley, 2004; Bales and others, 2009), and annual SMB observations at stake sites in the ablation zone along Kangerlussuaq transect (b; Van de Wal and others, 2012).

(Fettweis and others, 2013; Fig. 2). Thus, we take uncertainty in MARv3 surface mass balance as $\pm 15 \%$ at basin scale. MARv3 was run at a resolution of $25 \mathrm{~km}$ and forced every 6 hours by ERA-40 (European Centre for Medium-Range Weather Forecasts (ECMWF) re-analysis) (1958-78) and ERA-Interim (1979-2013) re-analysis data at its boundaries, as well as 6 hourly sea surface temperature and sea-ice cover within its domain. MARv3 infers a mean reference period surface mass balance of $335 \pm 34 \mathrm{Gta}^{-1}$ within the PARCA perimeter (Table 1).

Box and others (2013) reconstruct ice-sheet net accumulation from ice cores over the period 1600-2009. The spatial character of this reconstruction is obtained from calibrating the annual net accumulation time series of 86 ice cores to RACMO2 regional climate model output (Ettema and others, 2009; Fig. 1). This calibration results in reconstructed annual net accumulation fields that capture the spatial pattern of modelled accumulation fields, but are absolutely accurate at ice-core locations. In comparison to annual icecore-derived net accumulation values, the reconstructed net accumulation fields have a residual non-systematic error of $\sim 5 \%$. We conservatively take uncertainty in reconstructed net accumulation to be $10 \%$ at both the basin and ice-sheet scales. Within the PARCA parameter, this reconstruction infers a mean reference period surface mass balance of $330 \pm 33 \mathrm{Gta}^{-1}$ (Table 1). We average the modelled (Fettweis and others, 2013) and reconstructed (Box and others, 2013) estimates of net accumulation, as well as uncertainty within each basin to derive an estimate of mass input to each basin. This yields a combined model/ reconstruction input within the PARCA perimeter of $333 \pm 34 \mathrm{Gta}^{-1}$ during 1961-90.

We assess ice outflow from the PARCA perimeter using the 1995 in situ ice surface velocity measurements and the protocol of Thomas and others (2001). We calculate ice outflow ( $Q$ in $\mathrm{km}^{3} \mathrm{a}^{-1}$ ) at each of the 161 flux gates along the PARCA perimeter according to

$$
Q=(u \beta f) W H
$$

where $u$ is gate-averaged velocity (a mean of velocity observation at each side of the gate), $\beta$ is a dimensionless azimuth correction (ranging from 0 to 1 ) to isolate gateperpendicular velocity (from Thomas and others, 2001), $f$ is the dimensionless ratio of surface ice velocity to depthaveraged ice velocity (from Thomas and others, 2001), $W$ is gate width and $H$ is ice thickness. We interpolate ice thickness and associated uncertainty at each PARCA stake from the recently compiled ice2sea ice thickness dataset (Bamber and others, 2013). The ice thickness uncertainty analysis associated with this dataset marks a substantial improvement over that available to Thomas and others (2001) (Fig. 3). Around all the 161 PARCA gates used to assess net outflow, ice thicknesses interpolated from Bamber and others (2013) are an average of $10 \mathrm{~m}$ greater than those used by Thomas and others (2001), likely due to improved resolution of the bed rather than a substantial increase in ice thickness between epochs. Unlike Thomas and others (2001), however, we do not neglect the ice flux from flux gates though which velocities are 'reversed', indicating net ice inflow from peripheral ice caps towards the ice-sheet interior. The inflow to the PARCA perimeter from these relatively low-velocity gates is equivalent to $\sim 11 \pm 2 \mathrm{Gta}^{-1}$, composed of $1 \pm 0$ and $9 \pm 1 \mathrm{Gta}^{-1}$ of inflow into basins 3 and 4 , respectively, in East Greenland, and $1 \pm 0 \mathrm{Gta}^{-1}$ of inflow into basin 5 in South Greenland.

We arbitrarily take $\pm 2 \mathrm{ma}^{-1}$ as representative of the uncertainty in observed ice surface velocity at all PARCA stakes, which is reasonable for a multi-annual high-precision GPS survey. This uncertainty includes any potential biases stemming from intra- and interannual velocity variability, both of which are expected to be negligible above $2000 \mathrm{~m}$ (Doyle and others, 2014). We take uncertainty in the ratio of surface ice velocity to depth-averaged ice velocity $(f)$ as \pm 0.03 , the standard deviation of all stake values assumed by Thomas and others (2001). We linearly interpolate the uncertainty in ice thickness at each PARCA stake from Bamber and others (2013). The mean ice thickness uncertainty across all stake sites is $\pm 154 \mathrm{~m}$. We assume no uncertainty in the geometry-prescribed parameters of azimuth correction and gate width. We assume 


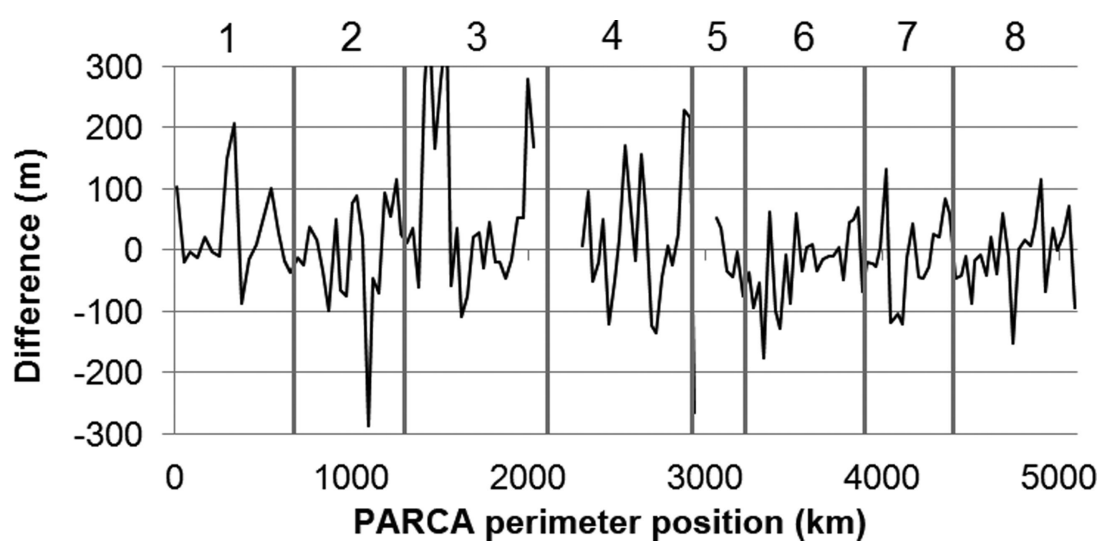

Fig. 3. Difference in ice thickness around the PARCA perimeter between Thomas and others (2001) and this study, which employs ice2sea ice geometry (Bamber and others, 2013). Numbers denote basins.

that the errors in each term used to calculate ice outflow from a given gate are independent and random, and can therefore be estimated as the quadratic sum of fractional uncertainties (Colgan and others, 2008). Within the PARCA perimeter, or a given basin, we sum the uncertainties of all gates to estimate total uncertainty in ice outflow. Given that the depth of porous firn $(<80 \mathrm{~m})$ is small relative to ice depth $(\sim 1500 \mathrm{~m})$ along the PARCA perimeter, we convert volume outflow to mass outflow using a bulk glacier density of $910 \mathrm{~kg} \mathrm{~m}^{-3}$ (Huss, 2013).

We combine our reassessed high-elevation mass balance with the analogous, fully independent, input-output estimate of Andersen and others (2015) to better assess high-elevation

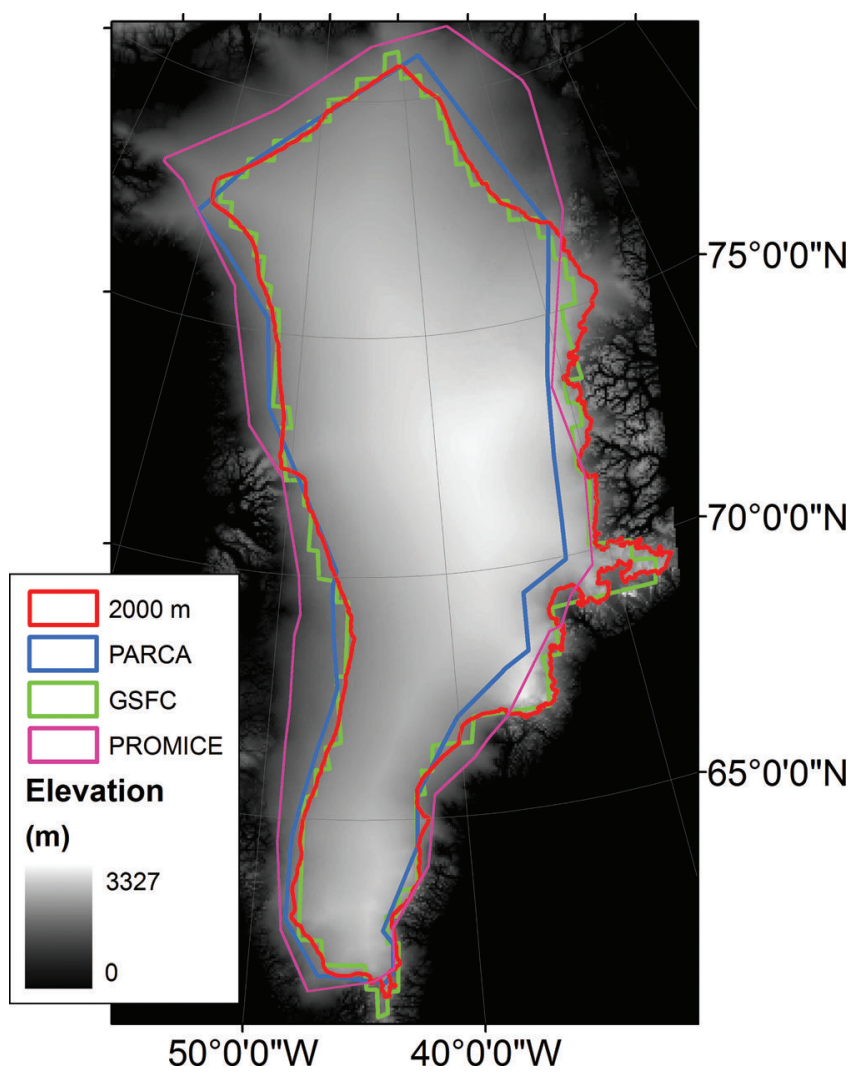

Fig. 4. Delineations of the high-elevation region of the Greenland ice sheet used by various studies (Table 2) overlaid on the ice2sea digital elevation model (Bamber and others, 2013). reference period mass balance. Andersen and others (2015) find a 1961-90 reference period high-elevation mass balance of $41 \pm 61 \mathrm{Gta}^{-1}$ using different ice-velocity, icethickness and surface mass-balance data from those that we employ. The Andersen and others (2015) estimate, however, pertains to the high-elevation area encompassed by flight lines collected under the Programme for Monitoring the Greenland Ice Sheet (PROMICE; Ahlstrøm and others, 2008). This high-elevation perimeter approximately follows the $1600 \mathrm{~m}$ ice surface elevation contour, enclosing an area of $12.7 \times 10^{5} \mathrm{~km}^{2}$ (Andersen and others, 2015; Fig. 4). By contrast, the higher-elevation area defined by the PARCA perimeter that we employ encloses an area of only $9.8 \times 10^{5} \mathrm{~km}^{2}$. Thus, these absolute estimates of highelevation mass balance are not directly comparable. We therefore correct both mass-balance estimates by their respective area and combine the probability density functions (PDFs) of the resultant specific (i.e. per unit area) mass balances.

In addition to combining our revised input-output estimate with that of Andersen and others (2015), we also place our revised estimate in the context of 11 previously published estimates of high-elevation mass balance. These elevation estimates differ in methodology, observational period and delineation of high-elevation area (Krabill and others, 2000; Thomas and others, 2000, 2001; Luthcke and others, 2006, 2013; Wouters and others, 2008; Schrama and Wouters, 2011; Sørensen and others, 2011; Zwally and others, 2011; Jacob and others, 2012; Csathó and others, 2014; Fig. 4). Across these diverse approaches, we assume published uncertainties correspond to $1 \sigma$ uncertainty, unless otherwise stated (Table 2). We are also forced to make some study-specific assumptions when converting published rates of thickness or volume change into equivalent rates of mass change (see Appendix). As the observational period varies widely between these studies, observed mass balance can be substantially influenced by surface mass-balance variability; changes in ice dynamics since 1961 are likely negligible at high elevations (Joughin and others, 2010). Thus, we cannot directly compare these more recent estimates with our reference period reassessment. An attempt to standardize diverse observational period mass balances to equivalent reference period mass balances using a surface mass-balance anomaly correction is problematic, because potentially spurious trends in modelled fields cannot be discounted with complete certainty (Bromwich and others, 2011), and 
Table 2. Observed mass balance of the high-elevation area of the Greenland ice sheet as assessed by recent studies of differing methodology, temporal period and spatial extent, listed by observational period. 'A' denotes altimetry, ' $\mathrm{G}$ ' denotes gravimetry and 'IO' denotes input-output. The area of each study is used to calculate specific mass balance (i.e. per unit area; Fig. 4)

\begin{tabular}{|c|c|c|c|c|c|}
\hline Study & Method & Period & $\begin{array}{c}\text { Balance } \\
\mathrm{Gta}^{-1}\end{array}$ & Area & $\begin{array}{c}\text { Balance } \\
\text { cm w.e. } \mathrm{a}^{-1}\end{array}$ \\
\hline This study & $1 \mathrm{O}$ & $1961-90$ & $54 \pm 46$ & PARCA & $6.1 \pm 5.2$ \\
\hline Andersen and others (2015) & $1 \mathrm{O}$ & $1961-90$ & $41 \pm 61$ & PROMICE & $3.5 \pm 5.3$ \\
\hline Thomas and others (2000) & $1 \mathrm{O}$ & 1970-95 & $-2 \pm 6$ & PARCA & $-0.2 \pm 0.7$ \\
\hline Thomas and others (2001) & $1 \mathrm{O}$ & 1970-95 & $0 \pm 21$ & PARCA & $0.0 \pm 2.4$ \\
\hline Krabill and others (2000) & A & 1994-99 & $1 \pm 14$ & $2000 \mathrm{~m}$ & $0.1 \pm 1.4$ \\
\hline Luthcke and others (2006) & G & 2003-05 & $41 \pm 8$ & GSFC & $4.6 \pm 0.9$ \\
\hline Wouters and others (2008) & G & $2003-07$ & $7 \pm 18$ & $2000 \mathrm{~m}$ & $0.7 \pm 1.8$ \\
\hline Zwally and others (2011) & $A$ & $2003-07$ & $21 \pm 1$ & $2000 \mathrm{~m}$ & $2.1 \pm 0.1$ \\
\hline Sørensen and others (2011) & A & $2003-08$ & $-2 \pm 8$ & $2000 \mathrm{~m}$ & $-0.2 \pm 0.8$ \\
\hline Csathó and others (2014) & $A$ & $2003-08$ & $16 \pm 5$ & PARCA & $1.8 \pm 0.6$ \\
\hline Schrama and Wouters (2011) & G & 2003-09 & $49 \pm 10$ & GSFC & $5.5 \pm 1.1$ \\
\hline Jacob and others (2012) & G & $2003-12$ & $11 \pm 10$ & $2000 \mathrm{~m}$ & $1.1 \pm 1.0$ \\
\hline Luthcke and others (2013) & G & $2004-10$ & $-7 \pm 9$ & GSFC & $-0.8 \pm 1.0$ \\
\hline
\end{tabular}

the amplitude of net accumulation variability in ice-corederived reconstructions can be suppressed at annual timescales, especially in low-accumulation regions like the Greenland interior (Box and others, 2013).

\section{RESULTS}

Across the high-elevation area enclosed by the PARCA perimeter, we assess a mean annual reference period surface mass balance (or mass input) of $334 \pm 34 \mathrm{Gta}^{-1}$ (Table 1). Thomas and others (2001) assess an analogous mass input of $\sim 264 \mathrm{Gta}^{-1}$ over the 1970-95 period. The mass input estimated by combining the regional climate model MARv3 with an independent ice-core-derived reconstruction is $27 \%$ greater than the mass input inferred by Thomas and others (2001). MARv3 indicates that mean annual surface mass balance within the PARCA perimeter was $\sim 5 \mathrm{Gt} \mathrm{a}^{-1}$ higher during 1970-95 compared with 196190. The majority of the discrepancy between the original and revised mass input estimates therefore stems from interpolation of sparsely distributed net accumulation estimates available to Thomas and others (2001).

We assess a 1995 mean annual ice outflow (or mass output) of $278 \pm 35 \mathrm{Gta}^{-1}$ from the PARCA perimeter. Thomas and others (2001) infer an analogous mass output estimate of $\sim 264 \mathrm{Gta}^{-1}$, in balance with net accumulation, but also provide an alternative outflow estimate of $\sim 288 \mathrm{Gta}^{-1}$ in online supplementary material. Thus, the ice outflow we assess is within the range assessed by Thomas and others $(2000,2001)$. Aside from differing ice thickness datasets, both our present estimate and that of Thomas and others $(2000,2001)$ employ identical data and methodology (Fig. 3). The only methodological difference is our inclusion of ten flux gates with a combined 'reverse' flow of $\sim 11 \pm 2 \mathrm{Gta}^{-1}$ towards the ice-sheet interior in basins 3,4 and 5 . We contend it is important to include these flux gates for consistency, to ensure characterization of outflow from the PARCA perimeter is as accurate as possible.

Differencing our calculated mass output estimate from our combined model and reconstruction mass input estimate infers a mass balance of $54 \pm 46 \mathrm{Gta}^{-1}$ within the PARCA perimeter during the 1961-90 reference period. This high-elevation mass-balance estimate is significantly greater than the $0 \pm 21 \mathrm{Gta}^{-1}$ mass-balance estimate of Thomas and others (2001). This difference reflects almost entirely an increase in estimated mass input due to the use of more positive surface mass-balance data in our revised assessment in comparison with Thomas and others (2001). We again note that the fully independent modelled and reconstructed net accumulation fields closely agree in assessing a net accumulation of $\sim 334 \mathrm{Gta}^{-1}$ within the PARCA perimeter during 1961-90. Of the eight major basins we examine, five appear to be gaining mass beyond uncertainty (basins 1, 2, 4, 5 and 6), and three appear to be within uncertainty of balance (i.e. $0 \mathrm{Gta}^{-1}$; basins 3, 7 and 8 ). No basins are losing mass beyond uncertainty (Table 1 ).

Combining the PDFs of the specific mass-balance estimate we present here $\left(6.1 \pm 5.2 \mathrm{~cm}\right.$ w.e. $\left.\mathrm{a}^{-1}\right)$ with that of Andersen and others $\left(2015 ; 3.5 \pm 5.3 \mathrm{~cm}\right.$ w.e. $\left.\mathrm{a}^{-1}\right)$ yields a best estimate of reference period high-elevation specific mass balance of $4.8 \pm 5.4 \mathrm{~cm}$ w.e. $\mathrm{a}^{-1}$ (Fig. 5). The PDF associated with this combined estimate infers an $81 \%$ likelihood to the scenario that high-elevation specific mass balance was positive during the 1961-90 reference period $\left(>0 \mathrm{~cm}\right.$ w.e. $\mathrm{a}^{-1}$ ) and a $70 \%$ likelihood to the scenario that

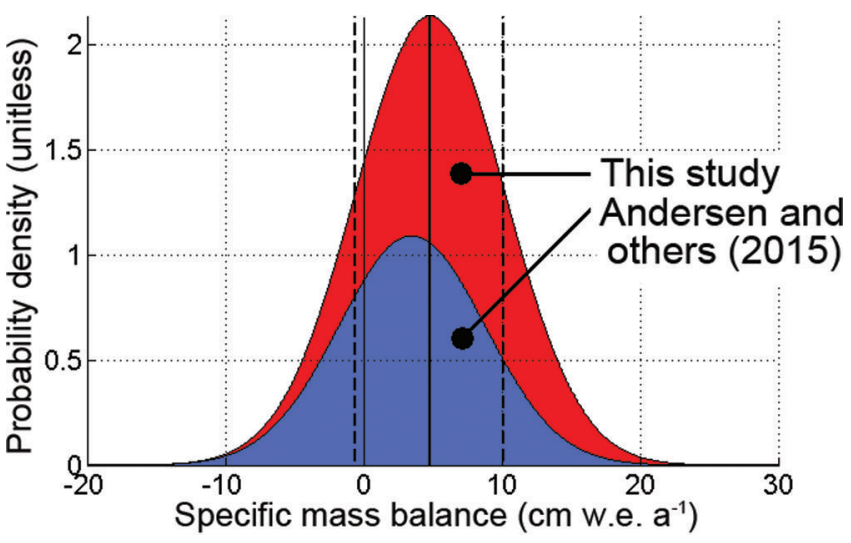

Fig. 5. Stacked PDFs of the input-output high-elevation mass balances of Andersen and others (2015) and this study during the 1961-90 reference period. Vertical lines denote the cumulative mean (solid) and $1 \sigma$ standard deviation (dashed). 
high-elevation specific mass balance exceeded $2 \mathrm{~cm}$ w.e. $\mathrm{a}^{-1}$ during the reference period. Distributed evenly across the $10.8 \times 10^{5} \mathrm{~km}^{2}$ of ice sheet above the $2000 \mathrm{~m}$ elevation contour, a $2 \mathrm{~cm}$ w.e. $\mathrm{a}^{-1}$ rate of thickening is equivalent to $20 \mathrm{Gta}^{-1}$ of mass gain during the reference period.

Of the 11 recent studies, of varying methodology and spatio-temporal extent, against which our reference period reassessment can be indirectly compared, five infer mass gain beyond uncertainty of zero (Luthcke and others, 2006; Schrama and Wouters, 2011; Zwally and others, 2011; Jacob and others, 2012; Csathó and others, 2014), two infer mass gain within uncertainty of zero (Krabill and others, 2000; Wouters and others, 2008) and three infer mass loss within uncertainty of zero (Thomas and others, 2000; Sørensen and others, 2011; Luthcke and others, 2013). No study infers mass loss beyond uncertainty of zero (Table 2). The high-elevation specific mass-balance rate we assess here $\left(6.1 \pm 5.2 \mathrm{~cm}\right.$ w.e. $\left.\mathrm{a}^{-1}\right)$ is higher than all previous studies. While the two 'post-PARCA' input-output studies infer a mean specific mass balance of $4.8 \pm 5.4 \mathrm{~cm}$ w.e. $\mathrm{a}^{-1}$, the four altimetry studies and five gravimetry studies infer significantly lower mean specific balances of $1.0 \pm 0.7$ and $2.2 \pm 1.2 \mathrm{~cm}$ w.e. $\mathrm{a}^{-1}$, respectively. Thus, the magnitude of high-elevation mass balance appears to be dependent on assessment method. We note that altimetry and gravimetry approaches are compelled to explicitly account for any longer-term trends in ice-sheet elevation and mass, while such trends are implicitly accounted for in an inputoutput approach.

\section{DISCUSSION}

Given that partitioning Greenland's ice loss into surface mass balance and ice discharge components is predicated on differencing contemporary surface mass balance or ice discharge from corresponding reference period values (e.g. Van den Broeke and others, 2009; Enderlin and others, 2014), an underestimation of either component during the reference period results in a direct underestimation of the contemporary sea-level rise contribution of that component since the reference period. Acknowledging a subtle massbalance trend is also important when assessing cumulative ice-sheet mass balance over centurial timescales (Box and Colgan, 2013). While a reference period mass imbalance of $\sim 20 \mathrm{Gt} \mathrm{a}^{-1}$ is relatively small in comparison with annual icesheet discharge or net surface mass balance $\left(\sim 500 \mathrm{Gta}^{-1}\right)$, it is non-trivial in comparison with total contemporary mass loss from the ice sheet proper $\left(\sim 250 \mathrm{Gta}^{-1}\right.$; Andersen and others, 2015), and even less trivial in comparison with the contemporary mass loss from the ice sheet proper attributed to either surface mass balance or ice dynamics. It is therefore desirable to examine whether subtle reference period mass gain may be attributed to either surface mass balance or ice dynamics, in order to gain insight into whether the contemporary ice loss due to either of these components may be underestimated.

\section{Attribution: surface mass balance}

Surface mass balance is often assumed to have been in nearequilibrium with ice dynamics during the 1961-90 reference period (e.g. Van den Broeke and others, 2009; Enderlin and others, 2014), with contemporary high-elevation thickening of the ice sheet being attributed to increasing snowfall rates as a consequence of a warming climate (e.g. Zwally, 1989;
Luthcke and others, 2006). Regional climate modelling, however, does not confirm a recent increase in net accumulation across the high-elevation region of the Greenland ice sheet (Vaughan and others, 2013). In contrast, while MARv3 estimates a mean annual surface mass balance of $335 \pm 34 \mathrm{Gta}^{-1}$ within the PARCA perimeter during the 1961-90 reference period, it assesses an equivalent value of $323 \pm 32 \mathrm{Gta}^{-1}$ during the 2004-10 study interval adopted by the Ice Mass Balance Inter-comparison Exercise (IMBIE; Shepherd and others, 2012). This recent net decrease of $\sim 12 \mathrm{Gta}^{-1}$ in high-elevation surface mass balance is composed of slight mass gain in North Greenland being more than offset by mass loss in South Greenland (Fig. 6). While the ERA-40 reanalysis data used to force MARv3 during the reference period are closely related to the ERAInterim data used to force MARv3 during the IMBIE period, the two climatology datasets are not identical (Fettweis and others, 2013). These differences are most likely insignificant with respect to interannual variability (Fig. 7). We must, however, acknowledge that a portion of the recent change in high-elevation mass balance simulated by MARv3 may reflect subtly different climate forcing in either epoch, which may be due to spurious trends or shifts in forcing parameters (Bromwich and others, 2011).

Ice-core reconstructions can place surface mass-balance variability in a broader temporal perspective. The Box and others (2013) reconstruction of net accumulation from 86 spatially distributed ice-core-derived records suggests that mean reference period surface mass balance within the $2000 \mathrm{~m}$ contour was $\sim 1 \%$ greater than the 1840-1999 mean $\left(359 \pm 35\right.$ and $354 \pm 72 \mathrm{Gta}^{-1}$, respectively; Fig. 8). On a centurial timescale, an assessment of decadal accumulation rate in four North Greenland ice cores (B26, Century, NEEM and NGRIP) indicates that mean annual accumulation rate during 1960-89 was $\sim 2 \%$ (or $\sim 0.5 \mathrm{~cm}$ w.e. $\mathrm{a}^{-1}$ ) greater than the 1900-99 mean (Buchardt and others, 2012; Fig. 9). On a millennial timescale, however, Greenland's high-elevation net accumulation rate during the 20th century was $\sim 2 \%$ less than the mean of the preceding ten centuries (Andersen and others, 2006). Indeed, this latter statistical optimization of the common signal of five ice cores (Crete, Dye-3, GRIP, Milcent and NGRIP) suggests that any 'distinct maxima' of anomalously high accumulation rates appears to have occurred at $\sim 1400$.

If a high-elevation mass imbalance of $\sim 20 \mathrm{Gta}^{-1}$ were solely attributable to surface mass-balance processes, this would infer a $\sim 7 \%$ surplus in long-term net accumulation relative to the revised long-term ice discharge presented here $\left(278 \pm 35 \mathrm{Gta}^{-1}\right)$. As high-elevation net accumulation during the 1961-90 reference period appears to have been within 1 or $2 \%$ of the centurial mean and approximately equal to the millennial mean (Andersen and others, 2006; Buchardt and others, 2012; Box and others, 2013), the subtle high-elevation mass gain we infer is unlikely to stem from anomalously high surface mass balance during the reference climatology period. Simply put, this confirms that high-elevation surface mass balance was characteristic of long-term mean and was not anomalous during 1961-90. Thus, surface mass balance was not a primary driver of subtle reference period mass imbalance.

\section{Attribution: ice dynamics}

Given negligible variability in ice dynamics above $2000 \mathrm{~m}$ elevation since 1961 (Joughin and others, 2010), any 


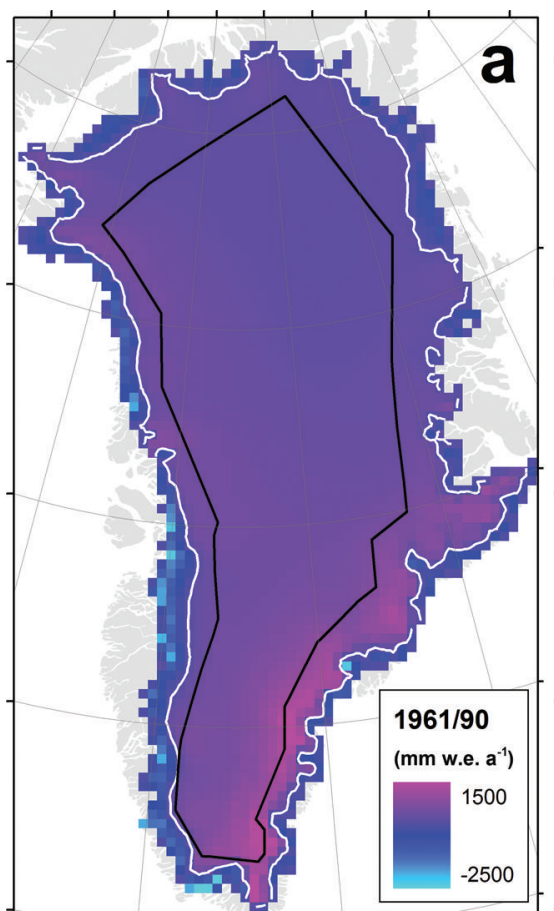

$50^{\circ} 0^{\prime} 0^{\prime \prime} \mathrm{W} \quad 40^{\circ} 0^{\prime} 0^{\prime \prime} \mathrm{W}$

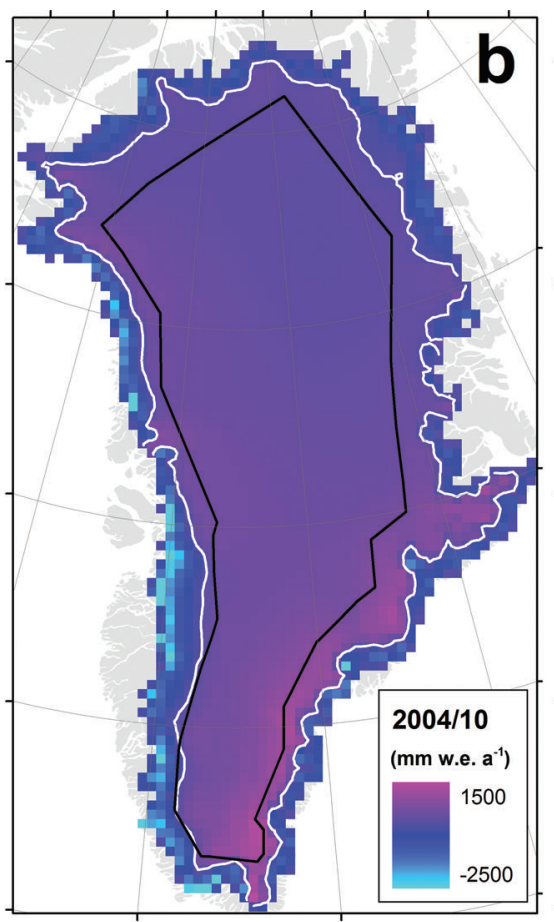

$50^{\circ} 0^{\prime} 0^{\prime \prime} \mathrm{W} \quad 40^{\circ} 0^{\prime} 0^{\prime \prime} \mathrm{W}$

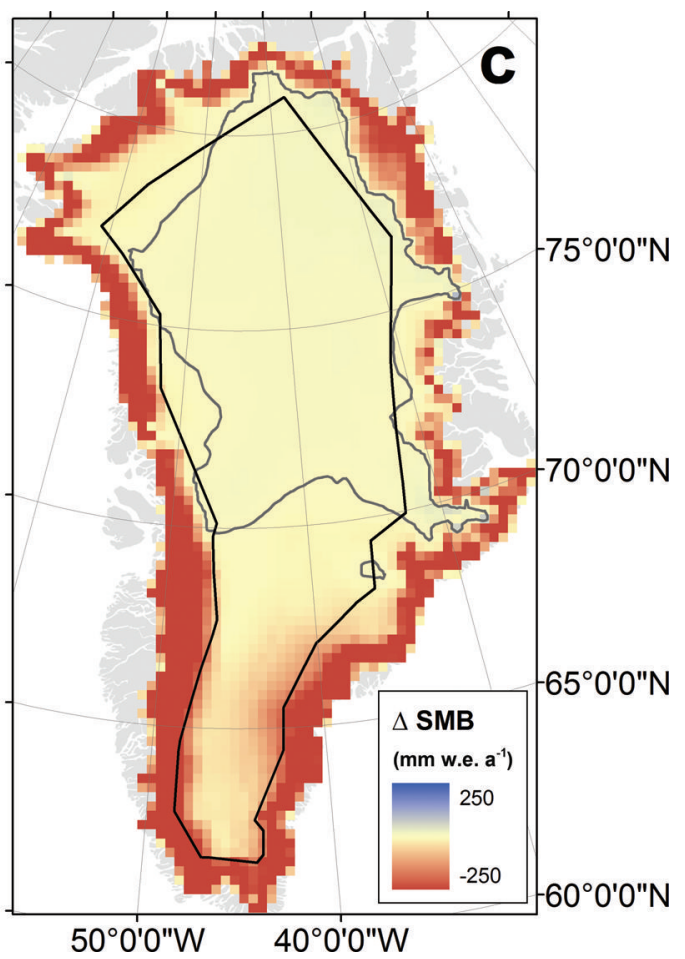

Fig. 6. MARv3-derived Greenland ice sheet surface mass balance during the 1961-90 reference climatology period (a) and the 2004-10 IMBIE period (b), and the difference relative to the reference period (c). Black lines denote PARCA perimeter, and grey/white lines denote zero contour. Colour bars saturate at minimum and maximum values.

high-elevation ice-dynamic mass gain must reflect longerterm (centurial or millennial) processes. There are theoretical (Reeh, 1985) and numerical modelling (Huybrechts, 1994) suggestions that millennial-scale ice-sheet thickening is an anticipated result of the downward advection through the ice sheet of the transition between relatively 'soft' Wisconsin ice and relatively 'hard' Holocene ice. This hypothesis has been invoked to explain both point- and basin-scale in situ mass-balance observations of decadalscale thickening in Greenland's accumulation area (Reeh and Gundestrup, 1985; Thomas and others, 2000). Potentially analogous long-term dynamic ice-cap thickening has been observed in the Canadian Arctic (Colgan and others, 2008).

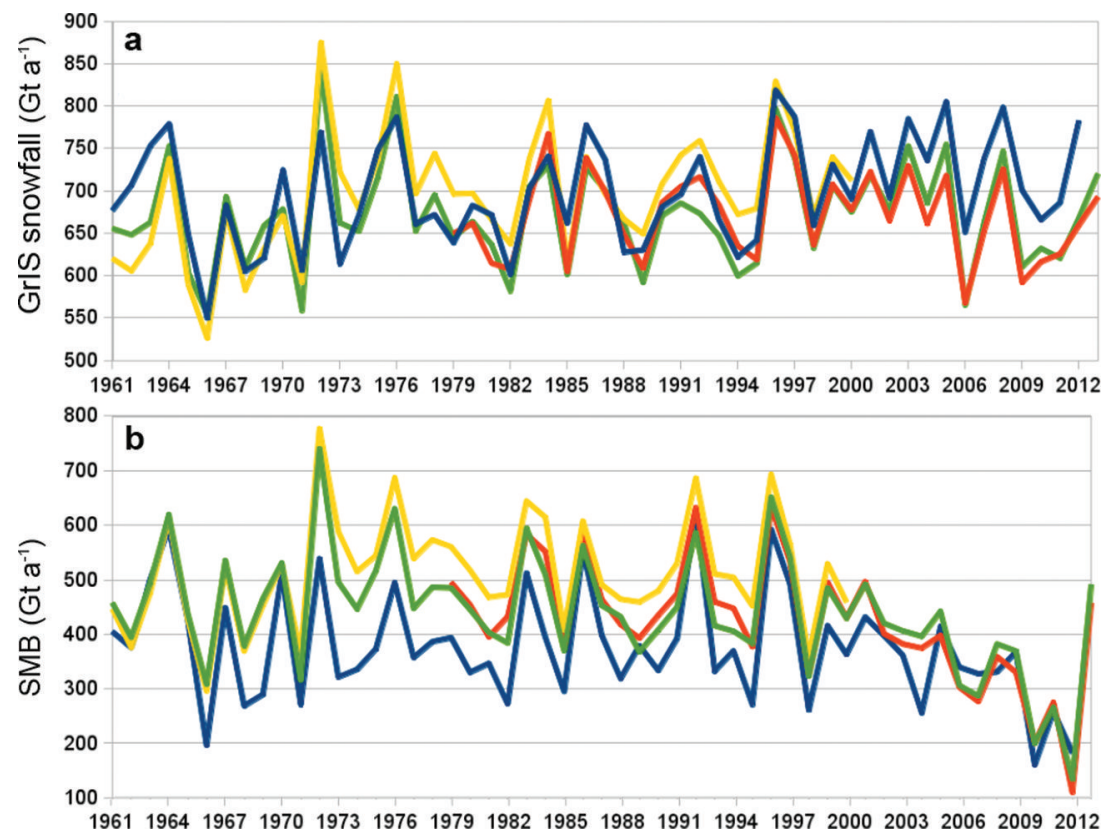

Fig. 7. Greenland ice sheet total snowfall (a) and surface mass balance (b) over 1961-2012 simulated by the regional climate model MARv3 when forced by four different climate reanalysis products: ERA-40 re-analysis (yellow; Uppala and others, 2005), ERA-Interim re-analysis (orange; Dee and others, 2011), Twentieth Century Re-analysis (blue; Compo and others, 2011) and NCEP/NCAR (US National Centers for Environmental Prediction/US National Center for Atmospheric Research) re-analysis (green; Kalnay and others, 1996). 


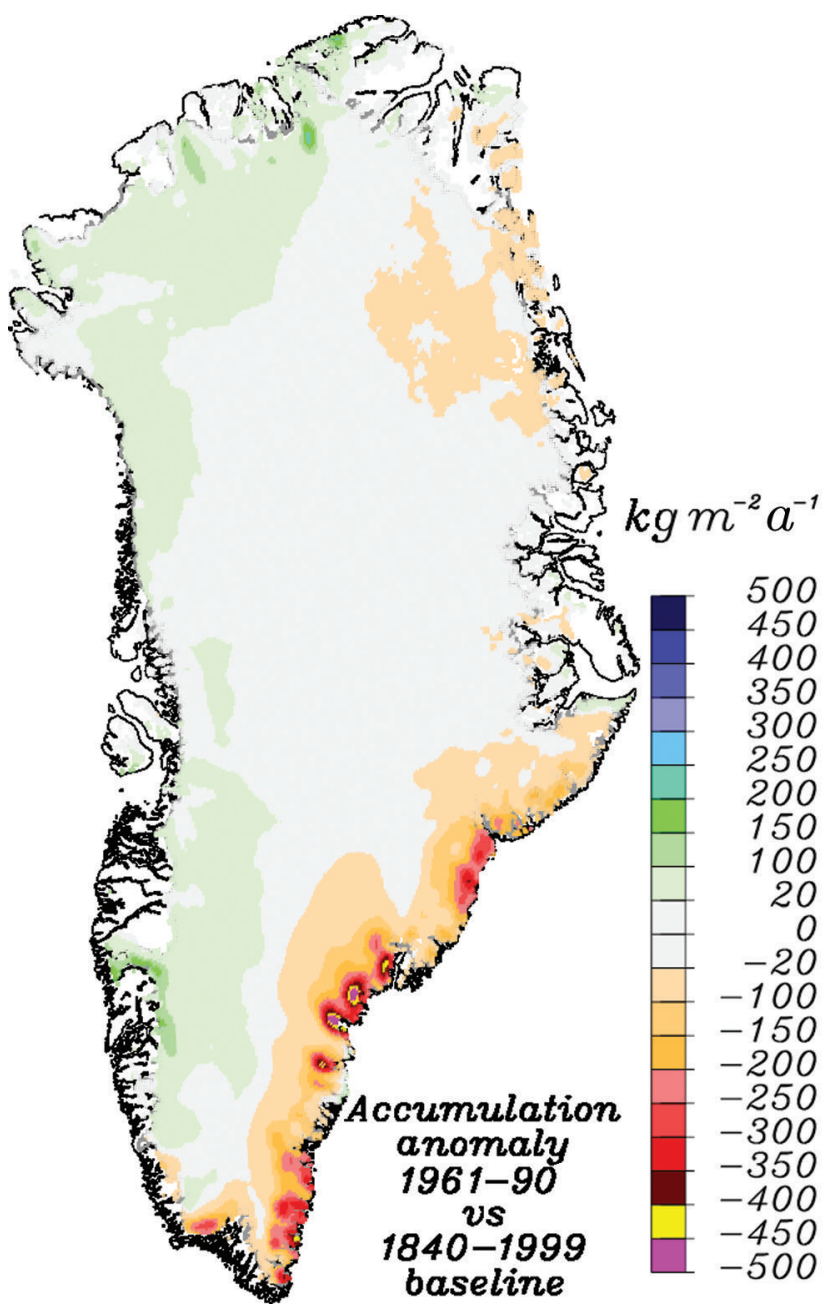

Fig. 8. The mean annual net accumulation of the 1961-90 reference period relative to the 1840-1999 reconstruction period of Box and others (2013).

Similar to Thomas and others (2000), our input-output assessment infers mass gain beyond uncertainty of zero balance in South Greenland basins 4, 5 and 6 (Table 1). The
Wisconsin-Holocene transition is currently moving through the deepest portions of the ice sheet in South Greenland ( $\sim 90 \%$ ice depth) compared with North Greenland ( 60\% ice depth; Huybrechts, 1994). As the majority of deformation occurs in the deepest $10 \%$ of the ice column, changes in deformation and consequently vertical flow and ice thickness theoretically are expected to be greater in South Greenland than North Greenland (Thomas and others, 2000). Transient changes in ice thickness due to ice dynamics are also expected to be greatest at flow divides, where ice flow is nearly vertical, and decrease with increasing ice surface slope until ice flow approaches surface-parallel at the equilibrium line and nearly horizontal at the ice margin (Fig. 10).

In an attempt to identify any potential ice-dynamic contribution to contemporary high-elevation mass gain, we compare 30 widely distributed in situ observations of mass balance with observed ice surface slope (Reeh and Gundestrup, 1985; Hamilton and Whillans, 2002; Morris and Wingham, 2011; Jezek, 2012; Table 3; Fig. 11). Ice surface slope is derived from the ice2sea dataset (Bamber and others, 2013). This comparison indicates that mass balance indeed decreases with increasing surface slope $(p<0.01 ; r=0.57$; degrees of freedom (d.f.) =29; Fig. 12). This is consistent with transient thickening in response to velocity decreases stemming from transient increases in ice viscosity. In contrast, when the in situ mass-balance observations are compared with mean reference period surface mass balance derived from MARv3 (Fettweis and others, 2013), local mass balance does not appear to be significantly correlated with surface mass balance $(p>0.10 ; r=0.04 ;$ d.f. $=29)$. This suggests that a fractional increase in net accumulation, such as that anticipated in response to a proportional increase in atmospheric moisture capacity, is not driving subtle mass gain (cf. Zwally, 1989; Box and others, 2013).

If a high-elevation mass imbalance of $\sim 20 \mathrm{Gta}^{-1}$ were solely attributable to ice-dynamic processes, this would imply that the revised ice outflow estimate we present $\left(278 \pm 35 \mathrm{Gta}^{-1}\right)$ is in deficit by $\sim 6 \%$ relative to an equilibrium flux of $308 \mathrm{Gta}^{-1}$. If distributed evenly over the $10.8 \times 10^{5} \mathrm{~km}^{2}$ of ice-sheet area above $2000 \mathrm{~m}$ elevation,

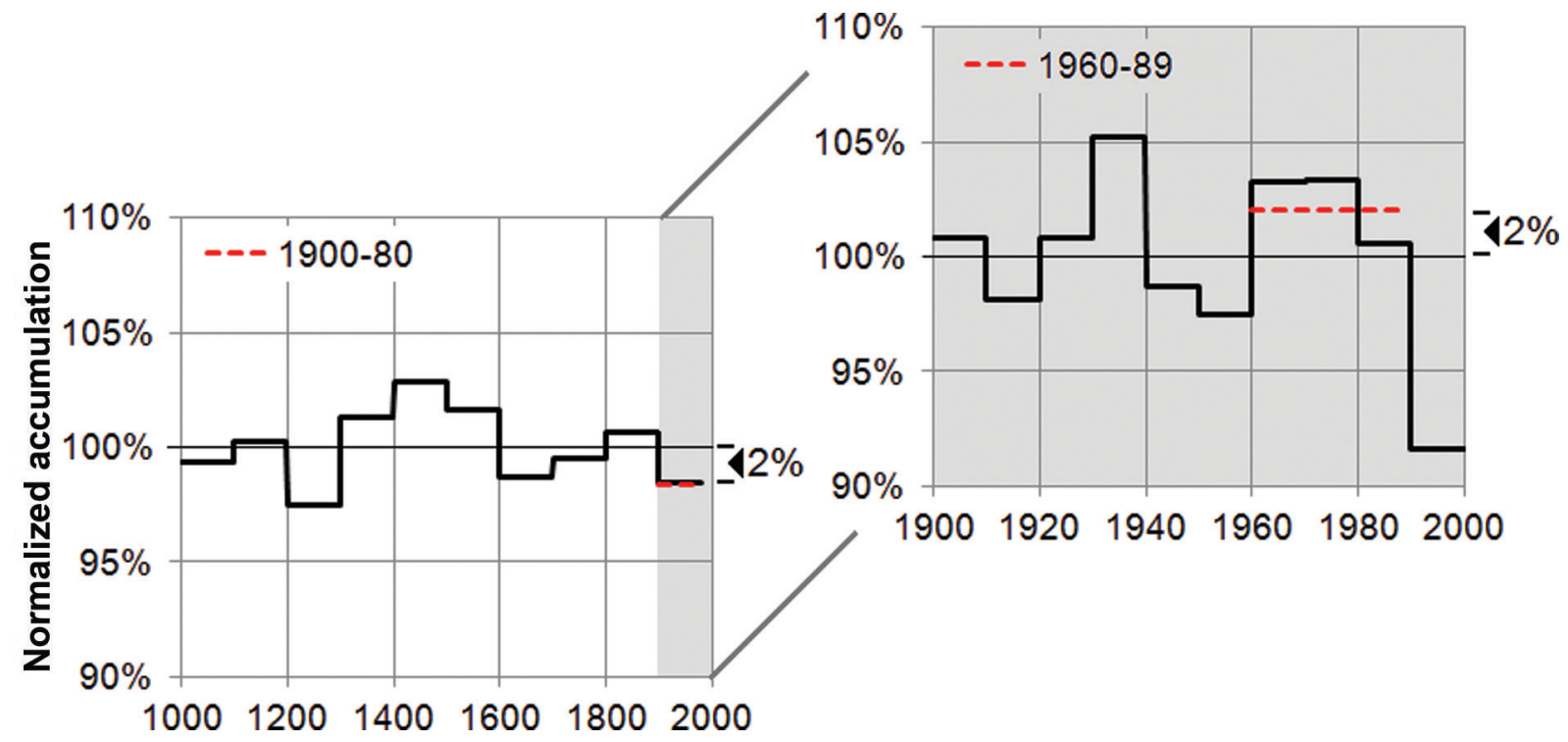

Fig. 9. Normalized Greenland high-elevation accumulation rate illustrating 1900-80 in the context of the past millennium (Andersen and others, 2006) and 1960-89 in the context of the past century (Buchardt and others, 2012). 


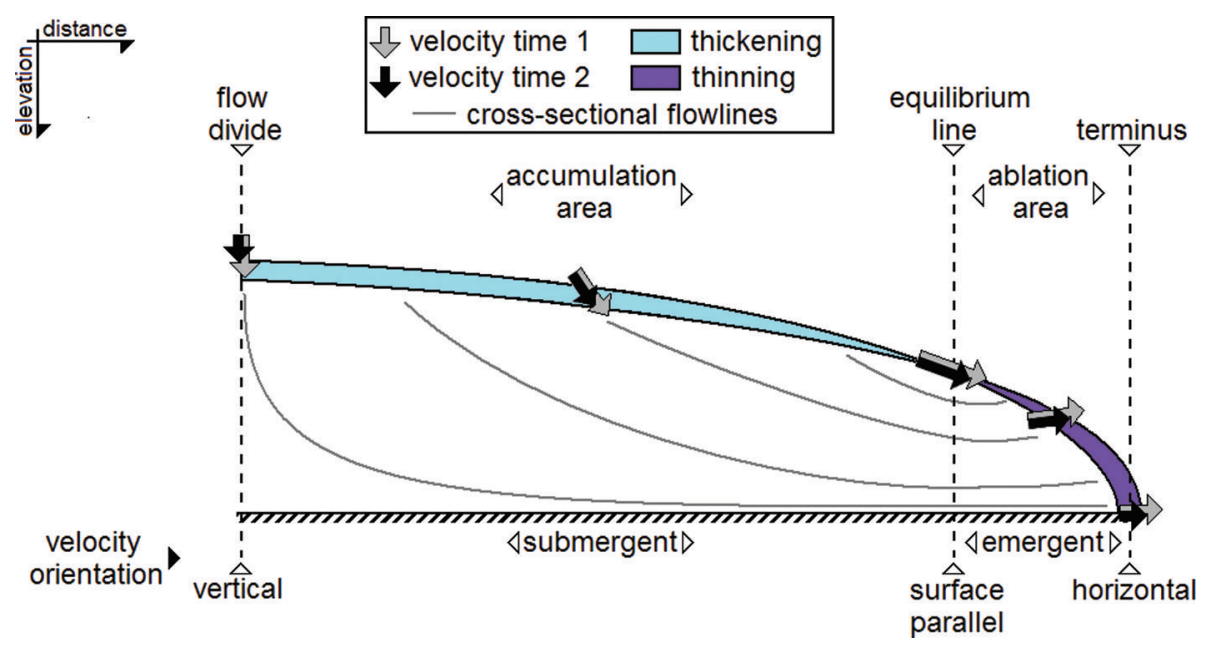

Fig. 10. Schematic of anticipated accumulation area thickening and ablation area thinning due to decreasing ice outflow from time 1 to time 2. Arrows denote cross-sectional velocity azimuth, illustrating the dependence of ice-dynamic thickening on surface slope. After figure 3.1 in Hooke (2005).

such a mass imbalance would represent $\sim 2 \mathrm{~cm}$ w.e. $\mathrm{a}^{-1}$ thickening due to ice dynamics. Reeh (1985) postulated that ongoing dynamic thickening, as a result of the downward advection of the Wisconsin-Holocene ice transition, was resulting in ice-sheet thickening 'presently at a rate of about $1 \mathrm{~cm} \mathrm{a}^{-1,}$ at Dye-3, Greenland. We suggest that millennial- scale ice dynamics are likely the primary driver of the subtle reference period high-elevation mass gain we observe because: (1) reference period accumulation rate appears to be characteristic of the millennial mean accumulation rate; and (2) in situ observations of mass balance appear to be dependent on slope rather than surface mass balance.

Table 3. Recent in situ mass-balance observations in the Greenland ice sheet accumulation area, listed by latitude

\begin{tabular}{|c|c|c|c|c|c|c|}
\hline Site & ID & $\begin{array}{l}\text { Latitude } \\
{ }^{\circ} \mathrm{N}\end{array}$ & $\begin{array}{c}\text { Longitude } \\
{ }^{\circ} \mathrm{E}\end{array}$ & $\begin{array}{c}\text { Balance } \\
\text { m w.e. } \mathrm{a}^{-1}\end{array}$ & Period & Source \\
\hline South Dome & 1 & 63.15 & -44.82 & $0.12 \pm 0.21$ & $\sim 1950-2000$ & 1 \\
\hline Dye-3 Divide & 2 & 64.85 & -44.65 & $0.05 \pm 0.08$ & 1980-2011 & 2 \\
\hline OSU Central & 3 & 65.11 & -45.69 & $-0.02 \pm 0.08$ & 2005-11 & 2 \\
\hline Dye-3 & 4 & 65.18 & -43.83 & $0.03 \pm 0.06$ & 〜 1883-1983 & 3 \\
\hline Dye-3 East & 5 & 65.26 & -43.47 & $-0.06 \pm 0.08$ & 1980-2011 & 2 \\
\hline OSU West & 6 & 65.39 & -47.67 & $-0.15 \pm 0.08$ & 2005-11 & 2 \\
\hline Saddle & 7 & 66.00 & -44.50 & $0.07 \pm 0.18$ & 〜1950-2000 & 1 \\
\hline Dye-2 & 8 & 66.50 & -46.27 & $0.08 \pm 0.17$ & $\sim 1950-2000$ & 1 \\
\hline Crawford Point & 9 & 69.88 & -46.97 & $-0.42 \pm 0.24$ & $\sim 1950-2000$ & 1 \\
\hline $\mathrm{T} 12$ & 10 & 70.18 & -45.34 & $-0.02 \pm 0.23$ & 2004-06 & 4 \\
\hline T15 & 11 & 70.30 & -44.57 & $0.25 \pm 0.23$ & 2004-06 & 4 \\
\hline T19 & 12 & 70.47 & -43.56 & $-0.06 \pm 0.22$ & 2004-06 & 4 \\
\hline T21 & 13 & 70.54 & -43.02 & $-0.13 \pm 0.26$ & 2004-06 & 4 \\
\hline T21A & 14 & 70.59 & -42.79 & $0.01 \pm 0.17$ & 2004-06 & 4 \\
\hline T23 & 15 & 70.63 & -42.58 & $-0.06 \pm 0.16$ & 2004-06 & 4 \\
\hline $\mathrm{T} 27$ & 16 & 70.78 & -41.54 & $-0.04 \pm 0.13$ & 2004-06 & 4 \\
\hline T31 & 17 & 70.91 & -40.64 & $-0.03 \pm 0.22$ & 2004-06 & 4 \\
\hline T35 & 18 & 70.98 & -39.55 & $0.06 \pm 0.23$ & 2004-06 & 4 \\
\hline T39 & 19 & 71.04 & -38.46 & $0.06 \pm 0.13$ & 2004-06 & 4 \\
\hline T41 & 20 & 71.08 & -37.92 & $0.18 \pm 0.25$ & 2004-06 & 4 \\
\hline T41A & 21 & 71.26 & -37.85 & $0.15 \pm 0.23$ & 2004-06 & 4 \\
\hline T41B & 22 & 71.61 & -37.71 & $0.00 \pm 0.25$ & 2004-06 & 4 \\
\hline Daugaard-Jensen & 23 & 71.88 & -32.05 & $-0.28 \pm 0.20$ & 1950-2000 & 1 \\
\hline $\mathrm{T} 41 \mathrm{C}$ & 24 & 71.97 & -37.57 & $0.06 \pm 0.21$ & 2004-06 & 4 \\
\hline Summit & 25 & 72.57 & -38.45 & $0.04 \pm 0.02$ & 〜1950-2000 & 1 \\
\hline T41D & 26 & 72.58 & -37.42 & $-0.05 \pm 0.25$ & 2004-06 & 4 \\
\hline NASA-U & 27 & 73.83 & -49.50 & $-0.02 \pm 0.15$ & $\sim 1950-2000$ & 1 \\
\hline NASA-E & 28 & 75.00 & -30.00 & $0.06 \pm 0.09$ & $\sim 1950-2000$ & 1 \\
\hline Camp Century & 29 & 77.24 & -61.03 & $-0.19 \pm 0.17$ & $\sim 1950-2000$ & 1 \\
\hline Humboldt & 30 & 78.53 & -56.83 & $0.02 \pm 0.07$ & 1950-2000 & 1 \\
\hline
\end{tabular}

Sources: 1. Hamilton and Whillans (2002); 2. Jezek (2012) (as presented by Colgan and others, 2014); 3. Reeh and Gundestrup (1985); 4. Morris and Wingham (2011). 


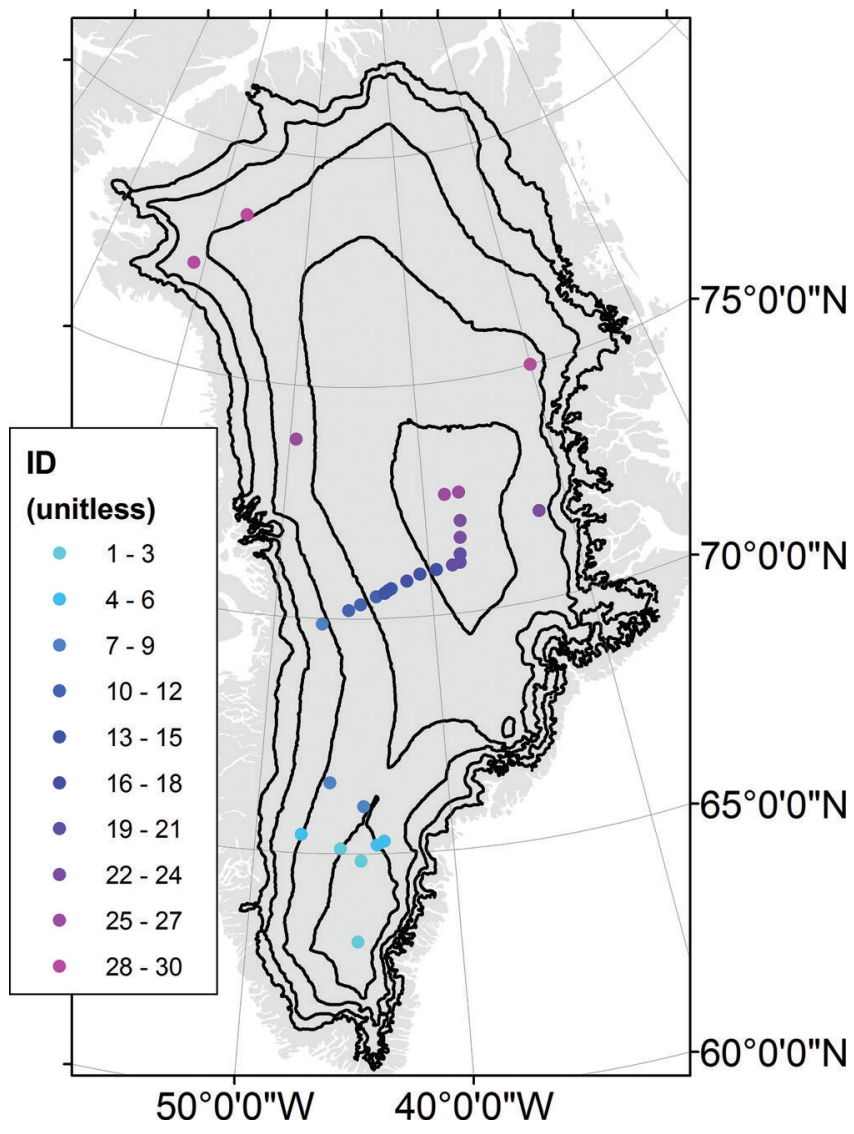

Fig. 11. Locations of stations listed in Table 3. Black lines denote ice-sheet elevation contours spaced every $500 \mathrm{~m}$ beginning at $1000 \mathrm{~m}$.

\section{SUMMARY: IMPLICATION FOR MASS LOSS PARTITION}

We have revisited the input-output estimate of highelevation mass balance within the PARCA perimeter established by Thomas and others $(2000,2001)$. Using new ice thickness data, regional climate modelling and an icecore-derived reconstruction, we assess a 1961-90 reference period mass balance within the PARCA perimeter of $54 \pm 48 \mathrm{Gta}^{-1}$. We have combined this estimate with an analogous input-output estimate of high-elevation mass balance that employs different velocity and ice thickness data, surface mass-balance forcing and high-elevation perimeter. Combining these fully independent estimates and their associated uncertainties yields a reference period highelevation specific mass balance of $4.8 \pm 5.4 \mathrm{~cm}$ w.e. $\mathrm{a}^{-1}$. This specific mass balance is greater than all but one satellitealtimetry- or gravimetry-derived estimate published to date. The PDF associated with our combined input-output estimate infers an $81 \%$ likelihood to the scenario that highelevation specific mass balance was positive during the 1961-90 reference period ( $>0 \mathrm{~cm}$ w.e. $\mathrm{a}^{-1}$ ) and a $70 \%$ likelihood that it was greater than $2 \mathrm{~cm}$ w.e. $\mathrm{a}^{-1}$.

It is difficult to conclusively attribute subtle reference period mass imbalance to either surface mass balance or ice-dynamic processes. However, given that (1) highelevation surface mass balance during 1961-90 appears to have been characteristic of the long-term mean (within 1 or $2 \%$ of the centurial mean and approximately equal to the millennial mean) and (2) in situ mass-balance observations exhibit a distinct surface slope rather than surface massbalance dependence, we suggest that millennial-scale ice dynamics are the primary driver of subtle reference period high-elevation mass gain. Evenly distributing $\sim 20 \mathrm{Gta}^{-1}$ of mass gain across the $>2000 \mathrm{~m}$ elevation area of the ice sheet yields a mean thickening rate $\left(\sim 2 \mathrm{~cm}\right.$ w.e. $\left.\mathrm{a}^{-1}\right)$ that is consistent with theoretical expectations of the ongoing thickening associated with the downward advection of the Wisconsin-Holocene ice transition (Reeh, 1985).

In order to explicitly acknowledge the role of millennialscale ice dynamics when partitioning recent Greenland ice loss, we suggest that the transient glacier continuity equation may be conceptualized as containing both shorter-term (ST) and longer-term (LT) ice dynamics components:

$$
\dot{m}=\dot{b}-\left(\nabla Q_{\mathrm{ST}}+\nabla Q_{\mathrm{LT}}\right)
$$

where centurial- to millennial-scale dynamic mass changes occurring during the reference period are attributed to longer-term ice dynamics $\left(\nabla Q_{\mathrm{LT}}\right)$, and annual- to decadal-scale dynamic mass changes occurring since the reference period are attributed to shorter-term ice dynamics $\left(\nabla Q_{\mathrm{ST}}\right)$.

Failure to acknowledge a potential $\sim 20 \mathrm{Gta}^{-1}$ reference period mass gain associated with longer-term ice dynamics would result in underestimating the recent Greenland ice loss due to shorter-term ice dynamics by $\sim 17 \%$ (96 versus $\left.116 \mathrm{Gta}^{-1}\right)$, and recent total Greenland ice loss by $\sim 7 \%$ (246 versus $266 \mathrm{Gta}^{-1}$; Table 4). Acknowledging a nontrivial longer-term ice-dynamic signal would imply that the surface mass-balance contribution to recent mass loss may
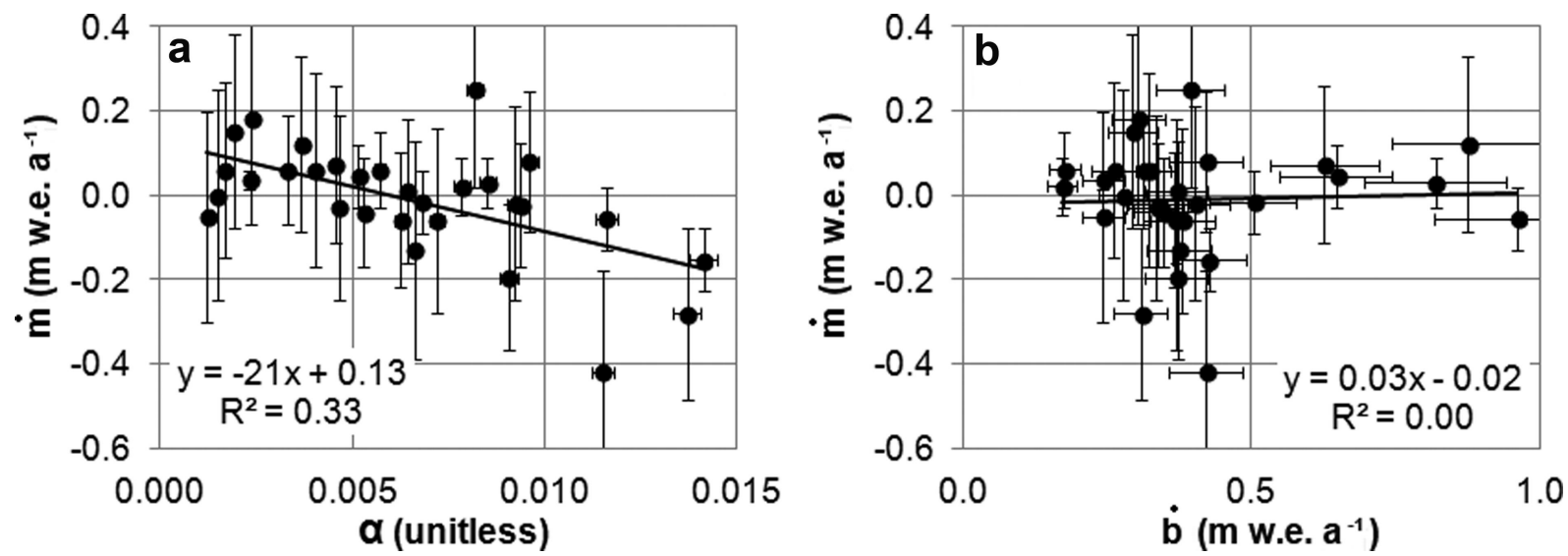

Fig. 12. In situ mass balance ( $\dot{m} ;$ Table 3$)$ versus surface slope $(\alpha ;$ a) and reference period surface mass balance $(\dot{b} ; b)$. 
Table 4. Implication of reference period mass imbalance on partitioning recent mass loss $(\dot{m})$ into surface mass-balance $(\dot{b})$ and ice-dynamic (or divergence of ice flux, $\nabla Q$ ) components. A base case (Enderlin and others, 2014) is contrasted with a scenario that acknowledges subtle longer-term dynamic imbalance $\left(\nabla Q_{\mathrm{LT}}>\right.$ $20 \mathrm{Gta}^{-1}$, Eqn (4)). Expressed in $\mathrm{Gta}^{-1}$

\begin{tabular}{lcccc}
\hline Case & Term & $\begin{array}{c}\text { Reference } \\
1961-90\end{array}$ & $\begin{array}{c}\text { Observed } \\
2000-12\end{array}$ & $\begin{array}{c}\text { Change since } \\
\text { reference }\end{array}$ \\
\hline Enderlin and others & $\dot{b}$ & 409 & 259 & -150 \\
(2014) & $\nabla Q$ & -409 & $-505^{*}$ & -96 \\
& $\dot{m}$ & 0 & -246 & -246 \\
Subtle longer-term & $\dot{b}$ & 409 & 259 & -150 \\
dynamic imbalance & $\nabla Q_{S T}$ & -409 & $-525^{*}$ & -116 \\
(Eqn (3)) & $\nabla Q_{\mathrm{LT}}$ & 20 & $20^{*}$ & 0 \\
& $\dot{m}$ & 20 & -246 & -266 \\
\hline
\end{tabular}

*The observed $2000-12 \nabla Q$ of $-505 \mathrm{Gta}^{-1}$ reflects both $\nabla Q_{\text {ST }}$ and $\nabla Q_{\mathrm{LT}}$.

have been only 1.3 times rather than 1.6 times greater than ice-dynamic mass loss during 2000-12 (Enderlin and others, 2014). Thus, even a relatively small mass imbalance of $\sim 20 \mathrm{Gta}^{-1}$ during the reference period has large implications on partitioning recent ice loss in a framework that does not account for centurial- to millennial-scale icedynamic signals. Acknowledging such a subtle mass trend is also important when assessing cumulative ice-sheet mass balance over centurial timescales (Box and Colgan, 2013).

Perhaps the overarching inference of our exploration of reference period imbalance is that the large uncertainty bounds associated with reference period high-elevation mass balance, coupled with the clear implication of neglecting subtle mass gain on partitioning recent Greenland ice loss, provide a strong impetus to seek better constraints on both the longer-term surface mass balance and ice-dynamic influences on high-elevation total mass balance. While the $>2000 \mathrm{~m}$ elevation ice-sheet area we considered accounts for only $\sim 58 \%$ of the extent of the Greenland ice sheet, most of the remaining ice-sheet area also resides within the accumulation area, where the downward advection of the Wisconsin-Holocene transition is also expected to contribute to millennial-scale thickening. Southwest Greenland, with primarily land-terminating ice, a relatively rich record of in situ surface mass-balance observations and the Wisconsin-Holocene ice transition at $\sim 90 \%$ ice depth, may offer the best chance to observe and quantify difficult to constrain long-term thickening rates.

\section{ACKNOWLEDGEMENTS}

We thank two anonymous reviewers whose comments greatly improved both the rigour and interpretation of our assessment of Greenland's high-elevation balance. We also thank Louise Sørensen for serving as our scientific editor. The work was funded by DFF FNU 11-115166, as well as the DANCEA Programme for Monitoring the Greenland Ice Sheet (PROMICE).

\section{REFERENCES}

Ahlstrøm AP and the PROMICE project team (2008) A new programme for monitoring the mass loss of the Greenland ice sheet. In Bennike $\mathrm{O}$ and Higgins AK eds. Review of survey activities 2007. (Geological Survey of Denmark and Greenland Bulletin 15) GEUS, Copenhagen

Andersen KK and 6 others (2006) Retrieving a common accumulation record from Greenland ice cores for the past 1800 years. J. Geophys. Res., 111(D15), D15106 (doi: 10.1029/ 2005JD006765)

Andersen ML and 10 others (2015) Basin-scale partitioning of Greenland ice sheet mass balance components (2007-2011). Earth Planet. Sci. Lett., 409, 89-95 (doi: 10.1016/ j.epsl.2014.10.015)

Bales RC and 8 others (2009) Annual accumulation for Greenland updated using ice core data developed during 2000-2006 and analysis of daily coastal meteorological data. J. Geophys. Res., 114(D6), D06301 (doi: 10.1029/2008JD010600)

Bamber JL and 10 others (2013) A new bed elevation dataset for Greenland. Cryosphere, 7(2), 499-510 (doi: 10.5194/tc-7-4992013)

Box JE and Colgan W (2013) Greenland ice sheet mass balance reconstruction. Part III: Marine ice loss and total mass balance (1840-2010). J. Climate, 26(18), 6990-7002 (doi: 10.1175/JCLID-12-00546.1)

Box JE and 10 others (2013) Greenland ice sheet mass balance reconstruction. Part I: net snow accumulation (1600-2009). J. Climate, 26(11), 3919-3934 (doi: 10.1175/ JCLI-D-12-00373.1)

Bromwich DH, Nicolas JP and Monaghan AJ (2011) An assessment of precipitation changes over Antarctica and the Southern Ocean since 1989 in contemporary global reanalyses. J. Climate, 24(6), 4189-4209 (doi: 10.1175/ 2011JCLI4074.1)

Buchardt SL, Clausen HB, Vinther BM and Dahl-Jensen D (2012) Investigating the past and recent $\delta^{18} \mathrm{O}$-accumulation relationship seen in Greenland ice cores. Climate Past, 8(6), 2053-2059 (doi: 10.5194/cp-8-2053-2012)

Cazenave A and Llovel W (2010) Contemporary sea level rise. Annu. Rev. Mar. Sci., 2, 145-173 (doi: 10.1146/annurevmarine-120308-081105)

Cogley JG (2004) Greenland accumulation: an error model. J. Geophys. Res., 109(D18), D18101 (doi: 10.1029/ 2003JD004449)

Colgan W, Davis J and Sharp M (2008) Is the high-elevation region of the Devon Ice Cap thickening? J. Glaciol., 54(186), 428-436 (doi: 10.3189/002214308785837084)

Colgan W and 7 others (2014) Hybrid inventory, gravimetry and altimetry (HIGA) mass balance product for Greenland and the Canadian Arctic. Cryos. Discuss., 8(1), 537-580 (doi: 10.5194/ tcd-8-537-2014)

Compo GP and 26 others (2011) The Twentieth Century Reanalysis Project. Q. J. R. Meteorol. Soc., 137(654), 1-28 (doi: 10.1002/ qj.776)

Csathó BM and 9 others (2014) Laser altimetry reveals complex pattern of Greenland Ice Sheet dynamics. Proc. Natl Acad. SCi. USA (PNAS), 11(52), 18478-18483 (doi: 10.1073/ pnas.1411680112)

Dee DP and 35 others (2011) The ERA-Interim reanalysis: configuration and performance of the data assimilation system. Q. J. R. Meteorol. Soc., 137(656), 553-597 (doi: 10.1002/qj.828)

Doyle SH and 6 others (2014) Persistent flow acceleration within the interior of the Greenland ice sheet. Geophys. Res. Lett., 41(3), 899-905 (doi: 10.1002/2013GL058933)

Enderlin EM, Howat IM, Jeong S, Noh M-J, Van Angelen JH and Van den Broeke MR (2014) An improved mass budget for the Greenland ice sheet. Geophys. Res. Lett., 41(3), 866-872 (doi: 10.1002/2013GL059010)

Ettema J and 6 others (2009) Higher surface mass balance of the Greenland ice sheet revealed by high-resolution climate modeling. Geophys. Res. Lett., 36(12), L12501 (doi: 10.1029/ 2009GL038110) 
Fettweis X and 6 others (2013) Estimating the Greenland ice sheet surface mass balance contribution to future sea level rise using the regional atmospheric climate model MAR. Cryosphere, 7(2), 469-489 (doi: 10.5194/tc-7-469-2013)

Hamilton GS and Whillans I (2002) Local rates of ice-sheet thickness change in Greenland. Ann. Glaciol., 35, 79-83 (doi: 10.3189/172756402781817383)

Huss M (2013) Density assumptions for converting geodetic glacier volume change to mass change. Cryosphere, 7(3), 877-887 (doi: 10.5194/tc-7-877-2013)

Huss M, Bauder A, Funk M and Hock R (2008) Determination of the seasonal mass balance of four Alpine glaciers since 1865. J. Geophys. Res., 113(F1), F01015 (doi: 10.1029/2007JF000803)

Huybrechts P (1994) The present evolution of the Greenland ice sheet: an assessment by modelling. Global Planet. Change, 9(1-2), 39-51

Jacob T, Wahr J, Pfeffer WT and Swenson S (2012) Recent contributions of glaciers and ice caps to sea level rise. Nature, 482(7386), 514-518 (doi: 10.1038/nature10847)

Jezek KC (2012) Surface elevation and velocity changes on the south-central Greenland ice sheet: 1980-2011. J. Glaciol., 58(212), 1201-1211 (doi: 10.3189/2012JoG12J031)

Joughin I, Smith BE, Howat IM, Scambos T and Moon T (2010) Greenland flow variability from ice-sheet-wide velocity mapping. J. Glaciol., 56(197), 415-430 (doi: 10.3189/ $002214310792447734)$

Kalnay E and 21 others (1996) The NCEP/NCAR 40-year reanalysis project. Bull. Am. Meteorol. Soc., 77(3), 437-471 (doi: 10.1175/ 1520-0477(1996)077<0437:TNYRP $>2.0$. CO;2)

Khan SA and 12 others (2014) Sustained mass loss of the northeast Greenland ice sheet triggered by regional warming. Nature Climate Change, 4(4), 292-299 (doi: 10.1038/nclimate2161)

Krabill WB and 9 others (2000) Greenland ice sheet: high-elevation balance and peripheral thinning. Science, 289(5478), 428-430 (doi: 10.1126/science.289.5478.428)

Luthcke SB and 8 others (2006) Recent Greenland ice mass loss by drainage system from satellite gravity observations. Science, 314(5803), 1286-1289 (doi: 10.1126/science.1130776)

Luthcke SB, Sabaka TJ, Loomis BD, Arendt A, McCarthy JJ and Camp J (2013) Antarctica, Greenland and Gulf of Alaska landice evolution from an iterated GRACE global mascon solution. J. Glaciol., 59(216), 613-631 (doi: 10.3189/2013JoG12J147)

Morris EM and Wingham DJ (2011) The effect of fluctuations in surface density, accumulation and compaction on elevation change rates along the EGIG line, central Greenland. J. Glaciol., 57(203), 416-430 (doi: 10.3189/002214311796905613)

Reeh N (1985) Was the Greenland ice sheet thinner in the Late Wisconsinan than now? Nature, 317(6040), 797-799 (doi: 10.1038/317797a0)

Reeh N and Gundestrup NS (1985) Mass balance of the Greenland ice sheet at Dye 3. J. Glaciol., 31(108), 198-200

Rignot E, Box JE, Burgess E and Hanna E (2008) Mass balance of the Greenland ice sheet from 1958 to 2007. Geophys. Res. Lett., 35(20), L20502 (doi: 10.1029/2008GL035417)

Schrama EJO and Wouters B (2011) Revisiting Greenland ice sheet mass loss observed by GRACE. J. Geophys. Res., 116(B2), B02407 (doi: 10.1029/2009JB006847)

Shepherd A and 46 others (2012) A reconciled estimate of ice-sheet mass balance. Science, 338(6111), 1183-1189 (doi: 10.1126/ science.1228102)

Sørensen LS and 7 others (2011) Mass balance of the Greenland ice sheet (2003-2008) from ICESat data - the impact of interpolation, sampling and firn density. Cryosphere, 5(1), 173-186 (doi: 10.5194/tc-5-173-2011)

Thomas R and 6 others (2000) Mass balance of the Greenland ice sheet at high elevations. Science, 289(5478), 426-428 (doi: 10.1126/science.289.5478.426)

Thomas R and 7 others (2001) Mass balance of higher-elevation parts of the Greenland ice sheet. J. Geophys. Res., 106(D24), 33 707-33 716 (doi: 10.1029/2001JD900033)
Uppala SM and 45 others (2005) The ERA-40 re-analysis. Q. J. R. Meteorol. Soc., 131(612), 2961-3212 (doi: 10.1256/ qj.04.176)

Van den Broeke $M$ and 8 others (2009) Partitioning recent Greenland mass loss. Science, 326(5955), 984-986 (doi: 10.1126/science.1178176)

Van de Wal RSW, Boot W, Smeets CJPP, Snellen H, Van den Broeke MR and Oerlemans J (2012) Twenty-one years of mass balance observations along the K-transect, West Greenland. Earth Syst. Sci. Data, 4(1), 31-35 (doi: 10.5194/ essd-4-31-2012)

Vaughan DG and 13 others (2013) Observations: cryosphere. In Stocker TF and 9 others eds. Climate change 2013: the physical science basis. Contribution of Working Group I to the Fifth Assessment Report of the Intergovernmental Panel on Climate Change. Cambridge University Press, Cambridge and New York

Vernon CL and 6 others (2013) Surface mass balance model intercomparison for the Greenland ice sheet. Cryosphere, 7(2), 599-614 (doi: 10.5194/tc-7-599-2013)

Wouters B, Chambers D and Schrama EJO (2008) GRACE observes small-scale mass loss in Greenland. Geophys. Res. Lett., 35(2), L20501 (doi: 10.1029/2008GL034816)

Zwally HJ (1989) Growth of Greenland ice sheet: interpretation. Science, 246(4937), 1589-1591 (doi: 10.1126/science.246. 4937.1589)

Zwally HJ and 11 others (2011) Greenland ice sheet mass balance: distribution of increased mass loss with climate warming; 2003-07 versus 1992-2002. J. Glaciol., 57(201), 88-102 (doi: 10.3189/002214311795306682)

Zwally HJ, Giovinetto MB, Beckley MA and Saba JL (2012) Antarctic and Greenland drainage systems. GSFC Cryospheric Sciences Laboratory, Greenbelt, MD http://icesat4.gsfc.nasa. gov/cryo_data/ant_grn_drainage_systems.php

\section{APPENDIX: CONVERSIONS AND ASSUMPTIONS}

Krabill and others (2000) estimate ' $1 \pm>5 \mathrm{~mm} \mathrm{a}^{-1}$ average thickening for the entire region above $2000 \mathrm{~m}^{\prime}$. We convert this thickening rate $\left(\mathrm{d} H / \mathrm{d} t=0.001 \mathrm{~m} \mathrm{a}^{-1}\right)$ into an equivalent mass gain of $1 \mathrm{Gta}^{-1}$ by assuming an area above the $2000 \mathrm{~m}$ contour of $10.8 \times 10^{5} \mathrm{~km}^{2}$ and a bulk ice density of $910 \mathrm{~kg} \mathrm{~m}^{-3}$. We take $1 \sigma$ uncertainty in $\mathrm{d} H / \mathrm{d} t$ as $0.010 \mathrm{ma}^{-1}$, or twice '>5 $\mathrm{mma}^{-1}$, for an associated uncertainty of $\pm 14 \mathrm{Gta}^{-1}$.

Thomas and others (2000) conclude that the almost 1 million $\mathrm{km}^{2}$ of the ice sheet within our area of study thinned by $2 \pm 7 \mathrm{~mm} \mathrm{a}^{-1}$ during the past few decades'. We convert this thinning rate $\left(\mathrm{d} H / \mathrm{d} t=-0.002 \mathrm{ma}^{-1}\right)$ with the survey area of $9.8 \times 10^{5} \mathrm{~km}^{2}$ specified by Thomas and others (2001) and a bulk ice density of $910 \mathrm{~kg} \mathrm{~m}^{-3}$ into an equivalent mass loss of $2 \mathrm{Gta}^{-1}$. We take $1 \sigma$ uncertainty in $\mathrm{d} H / \mathrm{d} t$ as $0.007 \mathrm{ma}^{-1}$ or an associated uncertainty of $\pm 6 \mathrm{Gta}^{-1}$.

Thomas and others (2001) present mean thickening rate (dH/dt) and 1970 to 1995 net accumulation rate (c) and their associated uncertainties in 12 zones of the highelevation area of the Greenland ice sheet. We employ a bulk ice density of $910 \mathrm{~kg} \mathrm{~m}^{-3}$ and published zone areas to calculate mass gain or loss in each zone. We sum the surface mass balance and mass gain or loss with associated uncertainty in all zones to yield a high-elevation massbalance estimate of $0 \pm 21 \mathrm{Gta}^{-1}$ (Table 5).

Sørensen and others (2011) present three volume-change to mass-change conversion methods. A personal communication from L. Sørensen (2014) advises that '[the authors] prefer the method M3 of the paper and applying the firn compaction'. We therefore take the -9 to $+6 \mathrm{Gta}^{-1}$ 
sensitivity range of mass balance above 2000 m elevation of the $\mathrm{M} 3$ method with firn compaction as equivalent to a best estimate of $-2 \mathrm{Gta}^{-1}$ with a $1 \sigma$ uncertainty of $\pm 8 \mathrm{Gta}^{-1}$ (where $8 \mathrm{Gta}^{-1}$ is half the -9 to $+6 \mathrm{Gta}^{-1}$ sensitivity range).

For the estimate of Jacob and others (2012), the mass balance of the ice sheet above $2000 \mathrm{~m}$ elevation was subsetted from an updated version of the dataset presented by Jacob and others (2012) spanning April 2003-April 2012. High-elevation signal was isolated by removing a spherical harmonic representation of an independent (non-GRACE) estimate of ice-sheet mass balance, fitting mascons (massconcentration parcels) to the residual field and then adding back the independent estimate of ice-sheet mass balance (Khan and others, 2014). This two-step filtering process reduces the contamination of relatively low-magnitude interior mass gain by relatively high-magnitude peripheral mass loss.

For the estimate of Csathó and others (2014), the mass balance of the high-elevation region delineated by the PARCA perimeter was subsetted from the dataset presented by Csathó and others (2014).
Table 5. Conversion of the rate of accumulation (c) and rate of thickness change $(\mathrm{d} H / \mathrm{d} t>)$ in Thomas and others (2001) into analogous zonal surface mass balance $(\dot{b})$ and mass balance $(\dot{m})$, and high-elevation totals

\begin{tabular}{|c|c|c|c|c|c|}
\hline Zone & $\begin{array}{l}\text { Area } \\
\mathrm{km}^{2}\end{array}$ & $\begin{array}{c}\mathrm{C} \\
\mathrm{cm} \mathrm{a}^{-1}\end{array}$ & $\begin{array}{l}\mathrm{d} H / \mathrm{d} t \\
\mathrm{~cm} \mathrm{a}^{-1}\end{array}$ & $\begin{array}{c}\dot{b} \\
\mathrm{Gta}^{-1}\end{array}$ & $\begin{array}{c}\dot{m} \\
\mathrm{Gta}^{-1}\end{array}$ \\
\hline A & 84463 & $16.0 \pm 0.8$ & $0.0 \pm 1.3$ & $12 \pm 1$ & $0 \pm 1$ \\
\hline B & 105541 & $12.6 \pm 0.7$ & $2.5 \pm 0.9$ & $12 \pm 1$ & $2 \pm 1$ \\
\hline C & 117372 & $14.2 \pm 0.7$ & $2.0 \pm 0.8$ & $15 \pm 1$ & $2 \pm 1$ \\
\hline D & 83680 & $19.4 \pm 1.0$ & $3.3 \pm 1.5$ & $15 \pm 1$ & $3 \pm 1$ \\
\hline$E$ & 30687 & $35.8 \pm 2.0$ & $-1.6 \pm 4.1$ & $10 \pm 1$ & $0 \pm 1$ \\
\hline $\mathrm{F}$ & 33809 & $51.5 \pm 4.0$ & $-10.6 \pm 6.2$ & $16 \pm 1$ & $-3 \pm 2$ \\
\hline G & 34061 & $67.0 \pm 6.0$ & $-28.5 \pm 7.9$ & $21 \pm 2$ & $-9 \pm 2$ \\
\hline $\mathrm{H}$ & 52957 & $59.7 \pm 6.0$ & $26.1 \pm 5.2$ & $29 \pm 3$ & $13 \pm 3$ \\
\hline I & 118917 & $39.9 \pm 5.0$ & $7.7 \pm 2.7$ & $43 \pm 5$ & $8 \pm 3$ \\
\hline J & 116401 & $38.2 \pm 1.5$ & $-6.5 \pm 2.7$ & $40 \pm 2$ & $-7 \pm 3$ \\
\hline K & 67387 & $29.9 \pm 1.7$ & $-1.5 \pm 2.8$ & $18 \pm 1$ & $-1 \pm 2$ \\
\hline L & 131774 & $27.3 \pm 1.5$ & $-6.4 \pm 1.7$ & $33 \pm 2$ & $-8 \pm 2$ \\
\hline Total & 977049 & $\mathrm{n} / \mathrm{a}$ & $\mathrm{n} / \mathrm{a}$ & $264 \pm 19$ & $0 \pm 21$ \\
\hline
\end{tabular}

